\title{
Arte na rua e desdobramentos
}

\author{
Art in the street and developments
}

Débora Souto Allemand ${ }^{1}$

Eduardo Rocha ${ }^{2}$

\section{RESUMO}

O texto tem o objetivo de dialogar sobre questões que as intervenções urbanas podem suscitar na relação entre cidade, arte, política, capitalismo e espectador, propondo uma revisão de literatura que aproxima os conceitos citados. Passa pela relação corpo-cidade, questionando a espetacularização da vida cotidiana, assim como faz um apanhado histórico a respeito de performance e dança na rua. Conclui a respeito das consequências que as intervenções urbanas são capazes de produzir.

Palavras-chave: Intervenções urbanas. Cidade. Política.

\section{ABSTRACT}

This work aims to dialogue about various questions that street art and urban interventions can evoke in relationship between city, art, politic, capitalism and viewer, proposing a literature review approaching the concepts mentioned. Talk about the relationship body-city, questioning the everyday life' spectacle, as does a historical overview about performance and dancing in the street. concludes about the consequences that urban interventions are capable of producing.

Keywords: Urban interventions. City. Politic.

1.

Professora substituta no curso de Dança-Licenciatura da UFPel. Mestre em Arquitetura e Urbanismo pela UFPel e Licenciada em Dança pela UFPel. Contato:

deborallemand@hotmail.com ORCID: http://orcid.org/ 0000-0001-8479-9822

2.

Professor na Faculdade de Arquitetura e Urbanismo e no Programa de PósGraduação em Arquitetura e Urbanismo da Universidade Federal de Pelotas. Doutor em Arquitetura.

Contato: amigodudu@yahoo.com.br ORCID: http://orcid.org/

0000-0001-5446-9515

Submetido em: 30/09/2016, aceito em: 03/11/2016. 
Entramos em cena para tratar da relação entre dança e cidade, num "aqui e agora" de experiência e na busca de atentar às transformações que acontecem a todo o momento quando estamos em contato com os espaços urbanos. Os cidadãos da cidade estão em constante troca e reconstituição, a partir do contexto em que residem. Somos bombardeados por informações que nos atravessam e nos transformam e empurrados pelo capitalismo para cada vez produzir e consumir mais. A maioria dos habitantes das cidades não tem experiência urbana ${ }^{3}$, apesar de passar grande parte do dia no trânsito indo de casa para o trabalho e vice-versa (BONDÍA, 2002).

Entender o mundo contemporâneo necessita, então, pensar sobre corpo sem separá-lo do contexto em que está imerso, pois esses dois estão em constante troca. Por isso, as cidades são importantes espaços de subjetivação, o que faz com que muitos movimentos de arte lutem pelo seu espaço na rua e, assim, também produzam a cidade. Alguns grupos modernistas e pós-modernistas discutiram sobre a democratização da arte e passaram a utilizar espaços alternativos ao teatro de palco italiano, entendendo que ir para a rua era também uma forma de fazer política. Situacionismo, happening, performance e Judson Church foram alguns desses grupos e movimentos. Propunham uma fusão entre as artes, rompiam com a arte tradicional e não desvinculavam a arte da vida (SILVA, 2005). Isso gerava uma mudança aos que caminhavam na rua: de pedestres a espectadores emancipados (RANCIÈRE, 2005), provocando novas formas de estar na cidade.

\section{Corpo-Espaço}

Fazendo um apanhado de teorias que tratam da relação entre corpo e espaço, pensa-se na Banda ou Faixa de Moebius ${ }^{4}$ (figura 1) como a materialização desse conceito contemporâneo de fluidez. Assim, conversando com as referências Britto (2013), Jacques (2008), Miranda (2008), Santos (2014) e Takahashi (2010), entende-se corpo e espaço como duas entidades que estão em constante troca.

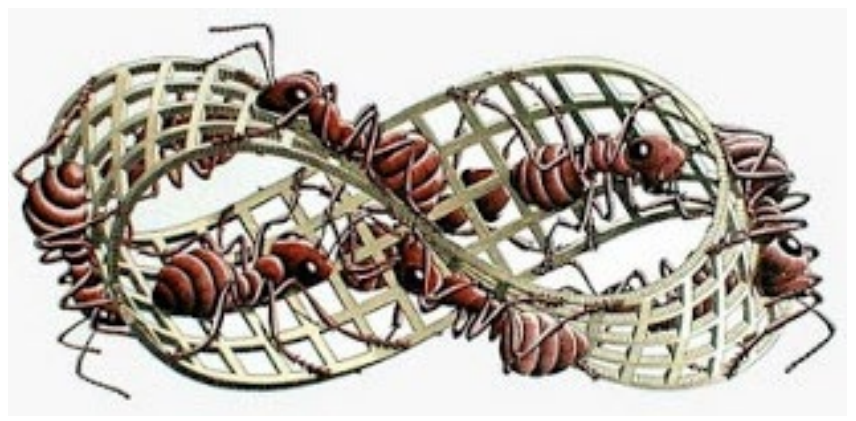

Figura 1. Banda de Moebius. Fonte: MATEMÁTICA CURIOSA. Acesso em: $26 /$ jun/2014.
3.

Experiência Urbana são as diversidades de sensações e trocas que a cidade pode proporcionar. Depois do Modernismo, as cidades em geral passaram a ser pensadas mais para os carros e para ser um local de trânsito de um lugar a outro e perderam essa característica do uso dos espaços públicos pelos habitantes.

4.

"A Faixa de Moebius é a mais elementar superfície não-orientável; e tem como característica ter apenas uma única e contínua margem" (SPERLING, 2003, p. 141). 
Para Milton Santos (2014), o espaço é composto de um conjunto de fixos e de um conjunto de fluxos, que se confundem e redefinem cada lugar:

Os elementos fixos, fixados em cada lugar, permitem ações que modificam o próprio lugar, fluxos novos ou renovados que recriam as condições ambientais e as condições sociais e redefinem cada lugar. Os fluxos são um resultado direto ou indireto das ações e atravessam ou se instalam nos fixos, modificando a sua significação e o seu valor, ao mesmo tempo em que também se modificam (SANTOS, 2014, Pp. 61 e 62).

Assim, os fixos seriam os objetos e os fluxos seriam os sujeitos na cidade, confundidos e misturados, fazendo com que a rua, o espaço e a arquitetura façam parte do corpo dos habitantes. Essa relação pode ser entendida como "Corpografia Urbana", um conceito que relaciona dança e urbanismo, mas que se afasta da ideia de cidade como um lugar em que o corpo se insere e a entende "como um campo de processos em que o corpo está coimplicado" (BRITTO, 2013, p. 37), ou seja, o espaço não é um vazio, está sempre em troca com o corpo que interage com ele.

A "corpografia urbana" é conceituada como uma cartografia corporal,

ou seja, parte da hipótese de que a experiência urbana fica inscrita, em diversas escalas de temporalidade, no próprio corpo daquele que a experimenta, e dessa forma também o define, mesmo que involuntariamente (JACQUES, 2008, s/p).

Tal concepção está relacionada ao conceito de "CorpoEspaço", de Miranda (2008, p. 24), que implica na fluidez das fronteiras corporais e do espaço. A autora compreende o movimento, o corpo e o espaço "permanentemente imersos em mútuas relações de transformação", como Jacques e Britto, que não entendem o corpo separado da cidade. A "corpografia urbana" sugere, então, que o corpo e a cidade configuram-se mutuamente; assim, a cidade fica inscrita nos corpos que interagem com ela, passando a ser também aqueles sujeitos: somos a cidade que experienciamos.

Para Takahashi (2010), o espaço não existe por si só, mas pode ser compreendido a partir da perspectiva do sujeito que o observa. E nessa relação, o observador não é passivo, já que, de acordo com o princípio da incerteza de Heisenberg5, "o simples ato de observação de um átomo já altera suas condições" (LIMA, 2003, p. 88). Devido a isso, no momento da observação, o sujeito passa a ser interagente, transformador daquele espaço.
5.

O princípio da incerteza de Heisenberg consiste num enunciado da mecânica quântica, formulado inicialmente em 1927, por Werner Heisenberg, impondo restrições à precisão com que se podem efetuar medidas simultâneas de uma classe de pares de observáveis em nível subatômico. 
Ainda assim, "o corpo foi esquecido nos dogmas urbanísticos dos anos 90, saturado pelas coordenadas funcionais da cidade e sufocado pelos sistemas de tráfego e circulação" (TAKAHASHI, 2010, p. 145). As cidades contemporâneas estão sendo planejadas de forma espetacular, distanciando os sujeitos do espaço urbano, com projetos que "buscam transformar os espaços públicos em cenários, espaços desencarnados, fachadas sem corpo: pura imagem publicitária" (JACQUES, 2010, p. 108). E a redução de seu uso afeta as dinâmicas sociais cotidianas, diminuindo a participação cidadã e a experiência corporal de apreensão da cidade. Dessa forma, a utilização da cidade de forma ativa pode influenciar significativamente na educação do sensível, possibilitando aos cidadãos a descoberta de seus corpos, sendo capazes de resistir ao corpo-mercadoria ${ }^{6}$.

\section{Arte de rua: um traçado}

A dança, em todas as épocas da história, passou por transformações de acordo com a forma de vida da humanidade. Com o nascimento das cidades não seria diferente: os ritos religiosos, que ocorriam através da dança, personalizam-se em grupos e "cada cidade terá seu rito, suas danças fixas". Essa mudança na forma de organização da sociedade modificou o sentido da dança: "da identificação com o 'espírito' [...] a um rito cívico, porque integrado à vida da cidade e comandado por ela" (BOURCIER, 2006, p. 10 e 12). Assim, através da dança, as cidades são responsáveis pela identificação de um grupo. Porém, quando a dança passou a ser considerada arte, ela se voltou aos espaços fechados de contemplação.

Em crítica à elitização da dança, que a confinou em espaços privados, por volta de 1950, na Europa, iniciou-se um movimento de retirada da arte dos museus e galerias, levando-a de volta para a rua, tendo como pano de fundo o Situacionismo ${ }^{7}$. Ainda na década de 1950, começa a ganhar vida o movimento chamado happening, uma proposta de fusão entre as artes, iniciado por John Cage ${ }^{8}$, com o propósito de conservar a individualidade de cada arte e ao mesmo tempo formar um todo separado, que funcionasse como outra linguagem. Cage aplica, então, suas ideias sobre o acaso, que já vinha trabalhando anteriormente com Merce Cunningham ${ }^{9}$ (GLUSBERG, 2005).

No primeiro evento organizado por Cage, em 1952, Untitled Event (Evento Sem Título), o espaço foi organizado de maneira diferente da habitual, de forma que os artistas pudessem circular por entre o público, diminuindo, dessa forma, a distância entre público e artista. A partir desse evento, muitos críticos e historiadores dos movimentos de vanguarda atri-
6.

Corpo-mercadoria é o corpo como objeto de consumo, para o qual se pensam produtos para a venda, ignorando o sujeito que é aquele corpo (JACQUES, 2008).

7 .

O Situacionismo foi um movimento que reuniu artistas de diversas áreas contrários à sociedade de consumo, à cultura espetacular e à passividade da sociedade. Comandados por Guy Debord, sugeriam que o "principal antídoto contra o espetáculo seria o seu oposto: a participação ativa dos indivíduos em todos os campos da vida social, principalmente no cultural" (JACQUES, 2012, p. 206). Além disso, "eram contra o monopólio urbano dos urbanistas e planejadores em geral, e a favor de uma construção realmente coletiva das cidades." (JACQUES, 2012, p. 209 e 210).

8.

John Cage era músico norte-americano e fazia experimentos com ruídos e sons cotidianos desde o final da década de 30 .

9.

Merce Cunningham encontra-se com John Cage em 1940.

Desde então, Cunningham assinala o fim de seu trabalho na

Companhia de Dança de Martha Graham e passa a trabalhar com Cage em experimentações de novas propostas de música, dança e performance (SILVA, 2005). 
buíram a Cage a incrível produção artística dos anos 1960 e 1970. Segundo Glusberg (2005), em declaração assinada por 50 autores de happenings da América, Europa e Japão em 1965:

Toda pessoa presente a um happening participa dele. É o fim da noção de atores e público. Num happening, pode-se mudar de "estado" à vontade. Cada um no seu tempo e ritmo. Já não existe mais uma "só direção" como no teatro ou no museu, nem mais feras atrás das grades, como no zoológico (GLUSBERG, 2005, p. 34).

Ainda fazendo parte do movimento happening, no final da década de 1950, artistas japoneses, reunidos no grupo Gutai, também experimentaram unir as diversas artes e fizeram propostas de live art, uma das formas de arte que merece destaque nos precursores da performance (GLUSBERG, 2005). A performance surge no início dos anos 1970 como forma de rompimento com a arte tradicional. As performances geralmente nasciam de improvisações, "[...] vinculados com o princípio básico de transformar o artista na sua própria obra, ou, melhor ainda, em sujeito e objeto de sua arte" (GLUSBERG, 2005, p. 43); assim, os artistas buscavam diminuir a distância entre vida e arte.

Para marcar os princípios da performance, dois acontecimentos ocorreram em 1962. Um deles foi o recital apresentado na Judson Memorial Church de New York pelos componentes do Dancers Workshop, que marcou o nascimento do Judson Dance Group (GLUSBERG, 2005). O outro foi a "fundação do movimento Fluxus, idealizado por George Maciunas, cujos 'concertos' mesclavam happenings (mais livres que os habituais), música experimental, poesia e performances individuais" (GLUSBERG, 2005, p. 38).

"A Judson Church Dance Theater nasceu de encontros entre estudantes de diversas linguagens artísticas, liderados por Robert Dunn" (MUNDIM, 2012, p. 102). A proposta do grupo era discutir novas formas de arte, criando alternativas para liberar a coreografia das amarras convencionais e das influências da dança moderna predominantes naquele período (MARTINS e MEYER, 2008). As ideias do grupo reverberaram significativamente na forma de fazer arte de John Cage, Steve Paxton, Yvonne Rainer e Trisha Brown, por exemplo, e, consequentemente, no tipo de dança que é feita hoje. O movimento tinha caráter interdisciplinar, fazendo surgir novas organizações artísticas e rompendo com os dualismos artificial-real, palco-plateia, criador-intérprete, processo-produto e cotidiano-cena. A partir de então, fortaleceu-se a ideia de utilização de espaços alternativos ao teatro para apresentações, incluindo a rua.

Já o grupo Fluxus foi um movimento formado por jovens norte-americanos, mas ativo também na Europa. Assim como 
o Judson Church, tinha uma proposta de redemocratização da arte, levando-a para o espaço público. A maioria dos artistas do grupo havia frequentado os cursos de John Cage, na Nova Escola de Investigações Sociais. O grupo realizava atividades em galerias, pequenos teatros, ruas e praças, incorporando todas as disciplinas - música, dança, happening, poesia, crítica, vídeo e artes plásticas. "Representou um momento decisivo da arte de vanguarda e marcou uma militância com todos os setores da criação artística" (GLUSBERG, 2005, p. 136), influenciando, inevitavelmente, a arte contemporânea.

Por sua vez, a arte da performance surgiu como resultado dos trabalhos dos artistas que centraram suas investigações no corpo. "A performance é um questionamento do natural e, ao mesmo tempo, uma proposta artística" (GLUSBERG, 2005, p. 58), que discutiu os dogmas comportamentais e influenciou na renovação do teatro, da música e da dança.

A partir desse momento, "a vida da sociedade será uma das maiores fontes de elementos para a arte da performance" (GLUSBERG, 2005, p. 72) e um dos temas mais utilizados como motivador para a dança de Trisha Brown, por exemplo. Considerada uma das fundadoras da dança pós-moderna, Trisha foi uma das artistas importantes que participaram da Judson Church. Suas obras foram apresentadas em locais alternativos tais como telhados, paredes, tetos, colunas e até estruturas montadas especialmente para suas apresentações. O destaque em suas coreografias foi a utilização das ações e movimentos diários habituais, a repetição, a utilização de espaços públicos alternativos que extrapolam os limites do palco, incluindo a forte característica de atenuar os limites entre a vida e a arte, através da apropriação do cotidiano. A coreógrafa libertou-se dos limites da caixa cênica com intuito de ampliar as possibilidades de movimento com o corpo, além de estabelecer outra forma de relação com o público (SILVA, 2005).

Brown, em 1965, influenciada por Cunningham, levou a dança para a rua entendendo-a como uma obra do acaso, onde os bailarinos não representavam, apenas faziam movimentos cotidianos em situações diferenciadas, como caminhar na parede, presos a equipamentos. $\mathrm{O}$ acaso viria das atividades que aconteciam na rua, onde não existem barreiras para definição desse tipo de espaço. Seria apenas mais um evento ocorrendo no espaço urbano, coexistindo com o resto, uma ação política: "arte que não vem com explicação ao lado" (ROSA, 2010, p. 50).

À luz do dia, sem figurino, sem anúncio, o homem apenas caminhava de cima a baixo, lentamente, enquanto durasse o percurso, já que não havia trilha nem soundscape $e^{10}$ para marcar o início ou o fim da função (ROSA, 2010, p. 49).
10.

Soundscape é uma palavra proveniente da língua inglesa, em português significa "Paisagem Sonora", que é formada pelos diferentes sons que compõem o ambiente. 
O espetáculo Walking on the wall (Caminhando na parede - figura 2) em 1970 colocou em xeque os limites entre dança e performance, propondo uma obra do acaso. Os bailarinos utilizavam equipamentos de escalada para caminhar na lateral de um edifício, obrigando os espectadores emancipados a apreciar a obra de ângulos não experimentados anteriormente. Além disso, Trisha discutiu a noção de espectador, já que a intervenção era realizada no espaço público e o transeunte poderia virar espectador ou não. Questionando essas barreiras, a artista estava fazendo um ato político, além de dança, performance ou o nome que se quisesse dar para a intervenção (ROSA, 2010). Essas características do trabalho provocaram diversas críticas e muitos se recusaram a chamar suas obras de dança (KATZ, 2013).
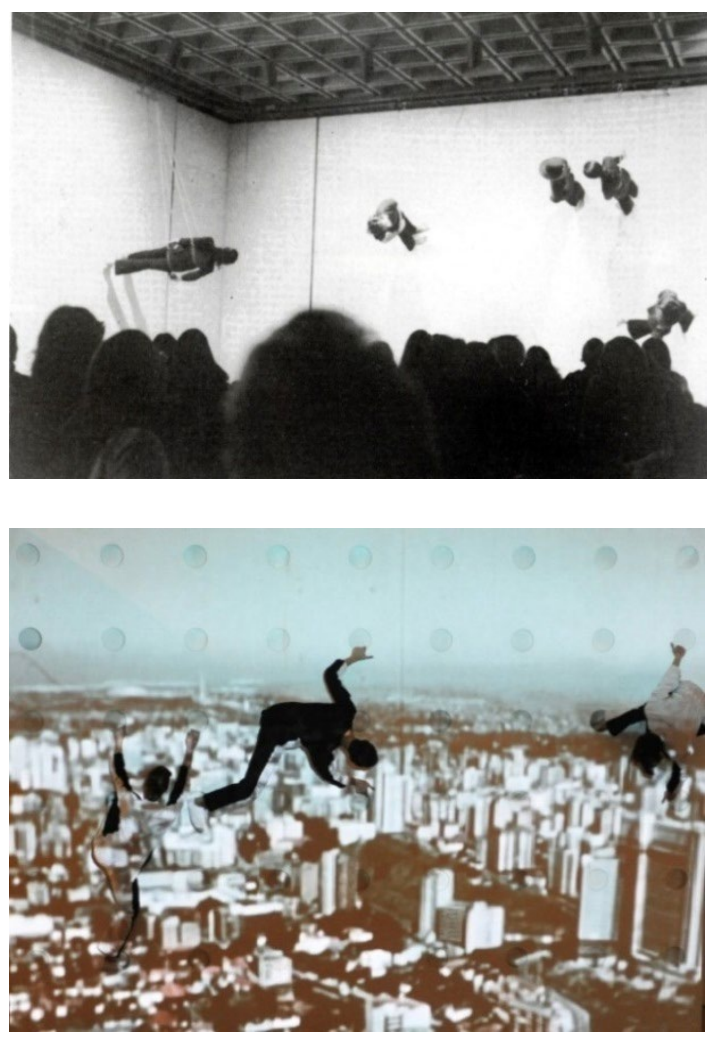

Figura 2.

Espetáculo Walking on the wall, 1970. Fonte: TRISHA BROWN COMPANY.

Acesso em: 10/nov/2014.

Outra obra que acarretou na discussão acerca do espaço urbano foi Roof Piece (figura 3), de 1971. Nessa intervenção, Brown toma como cenário para a performance alguns telhados de Manhattan, tendo como pano de fundo os edifícios e o efeito escultórico das caixas d'água que compõem o skyline ${ }^{11}$ da região. Além do que, o alcance do olhar era colocado em suspenso para abrir espaço ao espectador completar o desenvolvimento da performance em seu imaginário. Ao se aproximar do espaço urbano das cidades, dos movimentos cotidianos, pressupondo o corpo como intermediário de nossas relações com o mundo, a

11. Skyline é uma palavra proveniente da língua inglesa, que significa a linha do horizonte de uma cidade. 
coreógrafa procurava provocar uma participação ativa do observador em suas performances (DOBBERT, 2012, p. 450).

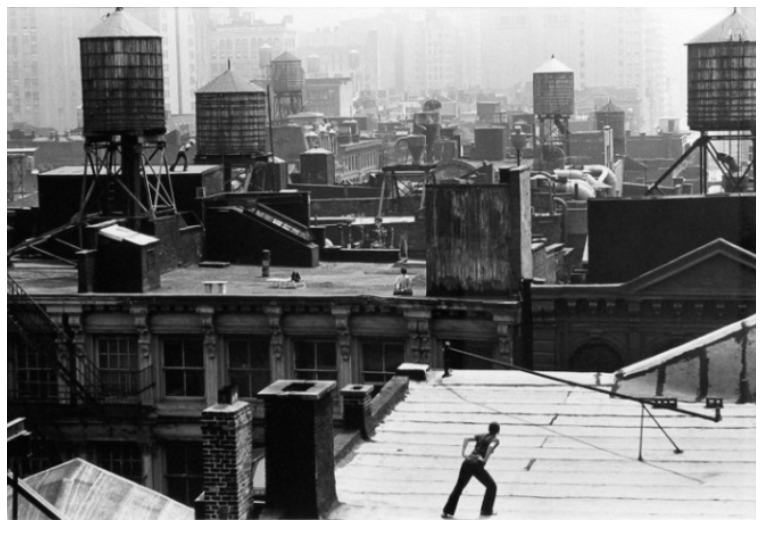

Figura 3.

Espetáculo Roof Piece, 1971. Fonte: TRISHA BROWN COMPANY. Acesso em: 10/nov/2014.

A Dança de Rua também se estabeleceu na década de 1970, apesar de uma das primeiras manifestações de Dança de Rua ter ocorrido em meio à crise de 1929, nos EUA, que acabou afetando o mundo quando muitos estabelecimentos foram obrigados a demitir seus funcionários para reduzir gastos. Entre esses funcionários estavam músicos e dançarinos que foram às ruas fazer shows para se sustentar. Entretanto, a explosão desse estilo de dança ocorreu na década de 1970, em Nova Iorque, com o movimento Hip Hop assumindo forma de protesto dos jovens pobres e negros, que acabou ganhando espaço em outras frentes com suas diversas manifestações (SANTOS, 2011).

No Brasil, a Dança de Rua surgiu no centro de São Paulo em 1984, com as primeiras manifestações de b.boys ${ }^{12}$ na Estação São Bento do Metrô, que posteriormente passaram a acontecer na Rua 24 de Maio esquina Dom José de Barros, ainda no centro de São Paulo. Esse se tornou o principal ponto de encontro dos dançarinos de rua, abrindo assim oficialmente as portas do Hip Hop no Brasil, por meio da Break Dance ${ }^{13}$ (SANTOS, 2011).

Na mesma época surgiu o Teatro de $\mathrm{Rua}^{14}$, lutando pela ruptura da ordem social da cidade e denunciando a cara segregacionista do sistema, que confinou os espetáculos teatrais em salas fechadas. O teatro de rua "recria o espaço da rua e inventa uma nova ordem, ao mesmo tempo em que impõe às pessoas que caminham pela rua uma mudança: de simples pedestres a espectadores" (CARREIRA, 2007, p. 41), gerando novas formas de estar na cidade. A partir de então diversos grupos de dança e teatro passaram a utilizar o espaço urbano como fomentador para a criação dos processos artísticos.

Assim, a arte na rua transforma o ambiente e têm função pública e política. Dilui as fronteiras entre as linguagens da arte, entre artista e espectador e, entre espaço cênico e espaço da plateia. A arte desterritorializa ${ }^{15}$ os que a experimentam, modifica valores da sociedade e potencializa uma nova forma

12.

B.boy é o termo utilizado para denominar os praticantes de breaking, um dos estilos da Dança de Rua.

13 .

Break Dance é um estilo de dança de rua, parte da cultura do Hip-Hop, criada por afroamericanos e latinos na década de 1970 em Nova Iorque, Estados Unidos.

14.

Teatro de rua é uma modalidade teatral realizada em espaços abertos da cidade, sobretudo em parques, praças, monumentos, edifícios, rios, entre outros, em oposição aos locais fechados.

15 .

Para Deleuze e Guattari (1997), desterritorializar significa lançar-se para fora de um território, daquilo que é familiar, em busca de outro lugar, outros territórios. 
de enxergar um "mesmo" espaço. Além disso, a cidade é lugar de múltiplos estímulos e, por isto, de grande potência para a criação artística, abrindo possibilidades de diferentes sensações e movimentos e produzindo diferentes formas de pensar com a dança (RIBEIRO, 2014). Surge, então, a ideia de Intervenção Urbana.

\section{Intervenção urbana e espectador emancipado}

Intervenção Urbana é uma "expressão que acontece no limbo da arte com a não-arte, aproximando-se e até confundindo-se com a vida, cujo lugar de realização é o espaço público" (RIBEIRO, 2014, p. 164). Nesse contexto, as obras de Intervenção Urbana não devem somente ser relacionadas com a temática da cidade, mas devem ser e transformar o ambiente em que estão se inserindo. Intervir implica em modificar algo, neste caso a rua e tudo àquilo que com ela conversa/interage e a constitui, como as relações sociais existentes no espaço público. Já a arte urbana e a arte pública têm a cidade como "ponto precursor" para as obras, mas esse espaço não está necessariamente embutido na poética.

A arte que vai para a rua, ou sitespecific, geralmente leva em consideração o contexto, o espaço com o qual compartilha, e assume "ela própria uma função pública" (BÜTTNER, 2002, p. 74). Esse tipo de arte faz pensar sobre o espaço, transformando-o a partir da crítica, mas também acabou se consolidando como um gênero de arte "cult", que transformou-se em arte espetacular ${ }^{16}$, não questionando a realidade preexistente:

Nesse processo de institucionalização e espetacularização de formas e atividades artísticas, as práticas de intervenção em espaço urbano começariam a participar nas estratégias de valorização da cidade, sendo assimiladas para a constituição de "identidades" urbanas e/ou de um clima atrativo de "agitação cultural" (SOUZA, 2011, p. 38).

De tal modo, a arte de rua pode perder seu viés político de resistência, entrando no sistema capitalista de estetização da cultura e da cidade. Ainda assim, as intervenções urbanas, em sua essência, são como agentes de produção de um discurso acerca da cidade. E, ao mesmo tempo, atuam em "dissonância ao sistema vigente de forças e representações que mantém uma determinada ordem, propondo relações diferenciadas de uso e de significado" (SOUZA, 2011, p. 32). As intervenções urbanas constroem os espaços públicos por engajarem pessoas em discussões e disputas políticas.

Alguns teóricos entendem que a contemporaneidade na
16.

Debord (2005) se coloca contra a ideia de espetáculo, pois entende que a essência do espetáculo é a externalidade e "quanto mais um homem contempla, menos vive; quanto mais aceita reconhecer-se nas imagens dominantes da necessidade, menos ele compreende a sua própria existência e o seu próprio desejo" (p. 19). Ou seja, o ser humano, que se preocupa com o exterior, esquece-se de voltar-se para si mesmo, deixando que outro o represente. Ele ainda observa que "o espetáculo não deseja chegar a nada que não seja ele mesmo" (p. 12). 
arte, independente da linguagem ou da superfície/matéria por onde ela se expressa, carrega uma ideia da antirrepresentação, ou seja, o artista revolucionário busca abolir a figuração, a representação da vida. Além do mais, o artista contemporâneo quer inventar uma nova realidade, já que representá-la torna-se uma tarefa impossível, pois não existe uma só realidade, nem um só espaço para todos.

Assim como a arte contemporânea não representa, o espectador também não só assiste uma obra de artes cênicas para tentar "entendê-la" - ele inventa uma história, tema ou sensação a partir daquilo que foi visto e da relação que foi estabelecida com a obra, dos agenciamentos feitos. Para Rancière (2008), ser espectador é uma coisa ruim, já que olhar é o oposto de conhecer e o oposto de agir, pois quem olha um espetáculo permanece imóvel em sua cadeira, sem nenhum poder de intervenção. Para o autor, aquele que assiste "deve ser impelido a abandonar o papel de observador passivo e assumir o papel de cientista que observa fenômenos e procura suas causas" (RANCIÈRE, 2008, s/p).

Existe uma dualidade nessa noção das artes do espetáculo, pois se pressupõe que exista alguém que realize uma ação e alguém que simplesmente a observe passivamente. Com este viés, Rancière propõe a noção de espectador emancipado, que dispensa a oposição entre olhar e agir, pois implica que olhar já é modificar algo, já é uma ação. O espectador ativo ou emancipado, então, "observa, seleciona, compara, interpreta. Ele conecta o que observa com muitas outras coisas que observou em outros palcos, em outros tipos de espaços" (RANCIÈRE, 2008, s/p). Essa proposição de romper com o dualismo dos papéis de espectador e artista também infere numa transformação espacial da obra de arte cênica, pois demanda que a performance possa vir a aconteça num espaço diferente do palco italiano, onde o artista está situado no alto e realiza uma ação e o espectador fica lá em baixo, sentado, somente observando.

Assim, no caso da arte de rua, não cabe falar de um "público em geral", mas de uma diversidade de pessoas que entram em contato com a obra, cada uma à sua maneira, algumas interrompendo sua caminhada para olhar, outras podem ser os próprios artistas que, por vezes, se colocam em outro lugar e, outras ainda, têm a possibilidade de serem atingidas sensorialmente de alguma forma, mesmo sem parar sua caminhada.

A arte na rua é também produtora de espaço urbano, pois "repercute as contradições, conflitos e relações de poder que o constituem" (PALLAMIN, 2002, p. 105). Podemos entender as intervenções urbanas como micropolíticas, desde que capazes de criticar as estruturas de poder e desafiar certos códigos de 
representação dominantes (figura 4), redefinindo, transformando espaços e criando outras realidades e culturas.

Um dos pontos de maior interesse é sua possibilidade de contribuir com a desregulação de certos valores aí cristalizados, gerando novas formas de esclarecimento e abrindo novas extensões do espaço vivido (PALLAMIN, 2002, p. 109).
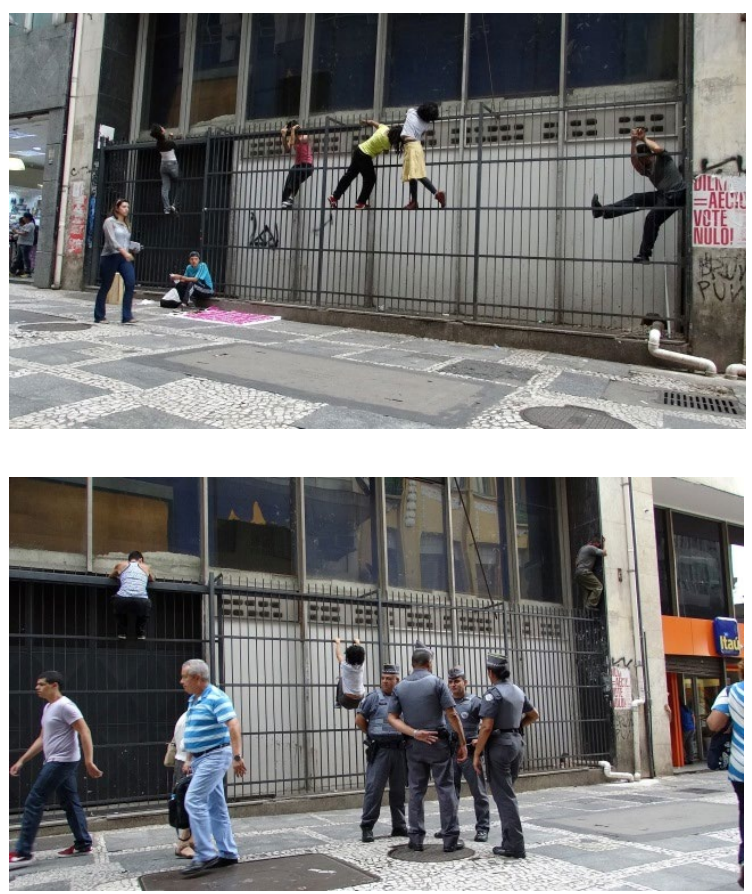
Figura 4.
...AVOA! Núcleo
Artístico, São Paulo-SP, 2014. Fonte: ....AVOA! NÚCLEO ARTÍSTICO. Acesso em: 13/ out $/ 2014$.
Figura 4. ...AVOA! Núcleo Artístico, São Paulo-SP, 2014. Fonte: ...AVOA! NÚCLEO ARTÍSTICO. Acesso em: 13/out/2014.

A arte de rua, por poder ser considerada uma forma de resistência, é uma das alternativas à forma contemporânea de globalização. Segundo Harvey (2014), essas alternativas virão de uma multiplicidade de espaços - urbanos, em particular -, que, combinadas em um movimento mais amplo, serão capazes de construir uma nova estrutura política de antimercantilização. A arte pode ser considerada como um dos movimentos que Harvey chama de "Teoria de Cupim" (2014), onde a transformação acontece de dentro para fora, vagarosamente, e, quando se vê, o "estrago já está feito". Mudanças como essas não são exterminadas pelo capital, pois não são consideradas ameaças óbvias.

Por conseguinte, as Intervenções Urbanas têm a capacidade de desterritorializar sujeitos, modificando valores cristalizados da sociedade e abrindo outras possibilidades de enxergar e constituir os espaços. "A todo momento, somos atravessados por esses campos finitos que nos 'retiram' da realidade cotidiana temporariamente" - a arte (REYES, 2005, p. 21). Arte como potência de criar novas realidades e de fazer o ser humano pensar, sentir, se "desautomatizar", ficar mais manual, braçal, corporal. 
Percebe-se, de acordo com o apanhado histórico aqui realizado, que diversos grupos de arte buscam na rua uma forma de aproximação da vida cotidiana. A rua passa a ser um espaço possível de fazer arte, tornando-se, assim, um lugar de afirmação desta e um território que permite as pontes entre arte, sociedade e política, dando ênfase a outro tipo de espectador de arte: o espectador emancipado. Na rua, a arte encontra-se com o cotidiano e desfaz-se a ideia de que vida cotidiana e arte são instâncias separadas. A apropriação das cidades como forma de resistência e de ampliação das possibilidades artísticas é uma maneira de lutar pela sensibilização e aprendizado através da arte. Uma forma de se fazer micropolítica. Arte não como representação, mas como dispositivo capaz de produzir afecções e pensamentos sobre o mundo em que se vive. Arte capaz de sensibilizar os cidadãos das cidades e, com isso, possibilitar bons encontros e relações potentes de troca entre as pessoas. Arte como potência criadora de realidades.

A arte de rua observa e valoriza a cidade onde está inserida e também a transforma a partir de suas apropriações. Compreende a realidade existente, a partir de sua lente, e a transgride, inventando outras realidades possíveis. Implicar os processos de criação artística aos espaços públicos é ler a cidade subjetiva contida nas brechas da cidade-espetáculo e, por conseguinte, ler a sociedade e a cultura que se fazem neste tempo contemporâneo. Fazer arte de rua é tornar visível nos corpos dos artistas as características do lugar e o modo de vida da sociedade, através da "corpografia urbana".

A arte de/na rua é, desta maneira, um potente dispositivo de transformação dos corpos, um dispositivo de fazer sentir e, com isso, uma possibilidade de escape, uma válvula que se abre de dentro do próprio sistema espetacular. Arte como forma de resistência ao que nos é imposto pelo capital e, por isso, arte como forma de fazer política na cidade. 
...AVOA! NÚCLEO ARTÍSTICO. Disponível em: http://avoaentrespacos.wordpress.com/Acesso em: 13/out/2014.

BONDÍA, Jorge Larrosa. Notas sobre a experiência e o saber de experiência. Rev. Bras. Educ. [online]. 2002, n.19, pp. 20-28.

BOURCIER, Paul. História da Dança no Ocidente. São Paulo: Martins Fontes, 2001.

BRITTO, Fabiana Dultra. A ideia de Corpografia Urbana como pista de análise. Redobra, Salvador, EDUFBA, nº 12, ano 4, 2013. BÜTTNER, Claudia. Projetos Artísticos nos Espaços Nãoinstitucionais de Hoje. In: PALLAMIN, Vera M. (Org.). Cidade e Cultura: esfera pública e transformação urbana. São Paulo: Estação Liberdade, 2002.

CARREIRA, André. Teatro de Rua: Brasil e Argentina nos anos 1980: Uma paixão no asfalto. São Paulo: Aderaldo \&Rothschild Editores Ltda., 2007.

DEBORD, Guy. A Sociedade do Espetáculo. Lisboa: Edições Antipáticas, 2005.

DELEUZE, Gilles e GUATTARI, Félix. Mil Platôs: capitalismo e esquizofrenia. V.4. São Paulo: Ed. 34, 1997.

GLUSBERG, Jorge. A arte da Performance. São Paulo: Perspectiva, 2005 .

HARVEY, David. Cidades Rebeldes: do direito à cidade à revolução urbana. Trad. Jeferson Camargo. São Paulo: Martins Fontes, 2014.

JACQUES, Paola Berenstein. Notas sobre Cidade e Cultura. In: ROCHA, Renata; RUBIM, Antonio Albino Canelas (Orgs.). Políticas Culturais para as Cidades. Salvador: EDUFBA, 2010.

JACQUES, Paola Berenstein. Elogio aos errantes. Salvador: EDUFBA, 2012.

JEUDY, Henri-Pierre. O corpo como objeto de arte. São Paulo: Estação Liberdade, 2002.

KATZ, Helena. Dança, Coreografia, Imunização. In: NOLF, Angela; MACEDO, Vanessa (Orgs.). Pontes Móveis: Modos de pensar a arte em suas relações com a contemporaneidade. São Paulo: Cooperativa Paulista de Dança, 2013.

LIMA, Dani. Corpos humanos não identificados: hibridismo cultural. In: Lições de dança 4. Rio de Janeiro: UniverCidade Editora, 2003.

MARTINS, Letícia; MEYER, Sandra. Viewpoints e educação somática: Conexões a partir de uma prática cênica. Revista DAPesquisa, v. 1, n. 3, Florianópolis, 2008. Disponível em: http:// 
www.ceart.udesc.br/revista_dapesquisa/volume3/numero1/ cenicas/leticia_sandrameyer.pdf. Acesso em: 02/07/14.

MIRANDA, Regina. Corpo-espaço: aspectos de uma geofilosofia do movimento. Rio de Janeiro: JLetras, 2008.

MUNDIM, Ana Carolina da Rocha. A composição em tempo real: um lugar de convívio artístico, político e afetivo. In: MUNDIM, Ana Carolina da Rocha (org.). Dramaturgia do corpo-espaço e territorialidade: uma experiência de pesquisa em dança contemporânea. Uberlândia: Composer, 2012.

PALLAMIN, Vera. Arte Urbana como Prática Crítica. In: PALLAMIN, Vera M. (Org.). Cidade e Cultura: esfera pública e transformação urbana. São Paulo: Estação Liberdade, 2002.

RANCIÈRE, Jacques. A partilha do sensível: estética e política. São Paulo: EXO experimental org./ Editora 34, 2005.

RANCIÈRE, Jacques. O espectador emancipado. Tradução de Daniele Avila Small do artigo de Jacques Rancière sobre a condição do espectador no teatro. Revista Questão de Crítica. V. 1. N. 3. Maio/2008. Disponível em: http://www.questaodecritica. com.br/2008/o5/o-espectador-emancipado/. Acesso em: 16/ mar/2016.

REYES, Paulo. Quando a rua vira Corpo [ou a dimensão pública na ordem digital]. Editora Unisinos: São Leopoldo, 2005.

RIBEIRO, Tiago Nogueira. Dança e Intervenção Urbana: a contribuição do regime dos editais para a espetacularização da arte e da cidade contemporânea. Redobra, Salvador, EDUFBA, $\mathrm{n}^{\circ}$ 14, ano 5, 2014.

ROSA, Tatiana Nunes da. A pergunta sobre os limites do corpo como instauradora da performance: propostas poéticas - e, portanto, pedagógicas - em dança. Dissertação do Curso de Mestrado em Educação da Universidade Federal do Rio Grande do Sul. Porto Alegre, RS: UFRGS, 2010.

SANTOS, Analu Silva dos. Dança de Rua: a dança que surgiu nas ruas e conquistou os palcos. 2011. Trabalho de Conclusão de Curso (Bacharelado em Educação Física), UFRGS, Porto Alegre.

SANTOS, Milton. A Natureza do Espaço: Técnica e Tempo, Razão e Emoção. 4 ed. São Paulo: Editora da Universidade de São Paulo, 2014.

SILVA, Eliana Rodrigues. Dança e pós-modernidade. Salvador: EDUFBA, 2005.

SOUZA, Gabriel Girnos Elias de. Territórios Estéticos: a experiência do Projeto Arte/Cidade em São Paulo (1994/2002). São Paulo: Annablume; Fapesp, 2011.

SPERLING, David Moreno. Arquiteturas Contínuas e Topologia: 
similaridades em processo. Dissertação de Mestrado do Programa de Pós-graduação em Tecnologia do Ambiente Construído. São Carlos: Escola de Engenharia de São Carlos, Universidade de São Paulo, 2003.

TAKAHASHI, Jo. Dimensões do corpo contemporâneo. In: GREINER, Christine; AMORIM, Cláudia (Orgs.). Leituras do corpo. 2 ed. São Paulo: Annablume, 2010.

TRISHA BROWN COMPANY. Disponivel em: http://www. trishabrowncompany.org/index.php?section=50\# main Acesso em: 10/nov/2014. 